\title{
Correction to: Data dependencies for query optimization: a survey
}

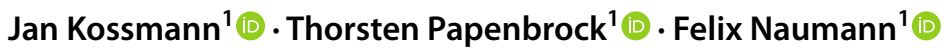

Published online: 28 December 2021

(c) Springer-Verlag GmbH Germany, part of Springer Nature 2021

\section{Correction to: The VLDB Journal https://doi.org/10.1007/s00778-021-00676-3}

The original article has been updated.

The original article was published with an error in Table 1.

The correct Table is given below.

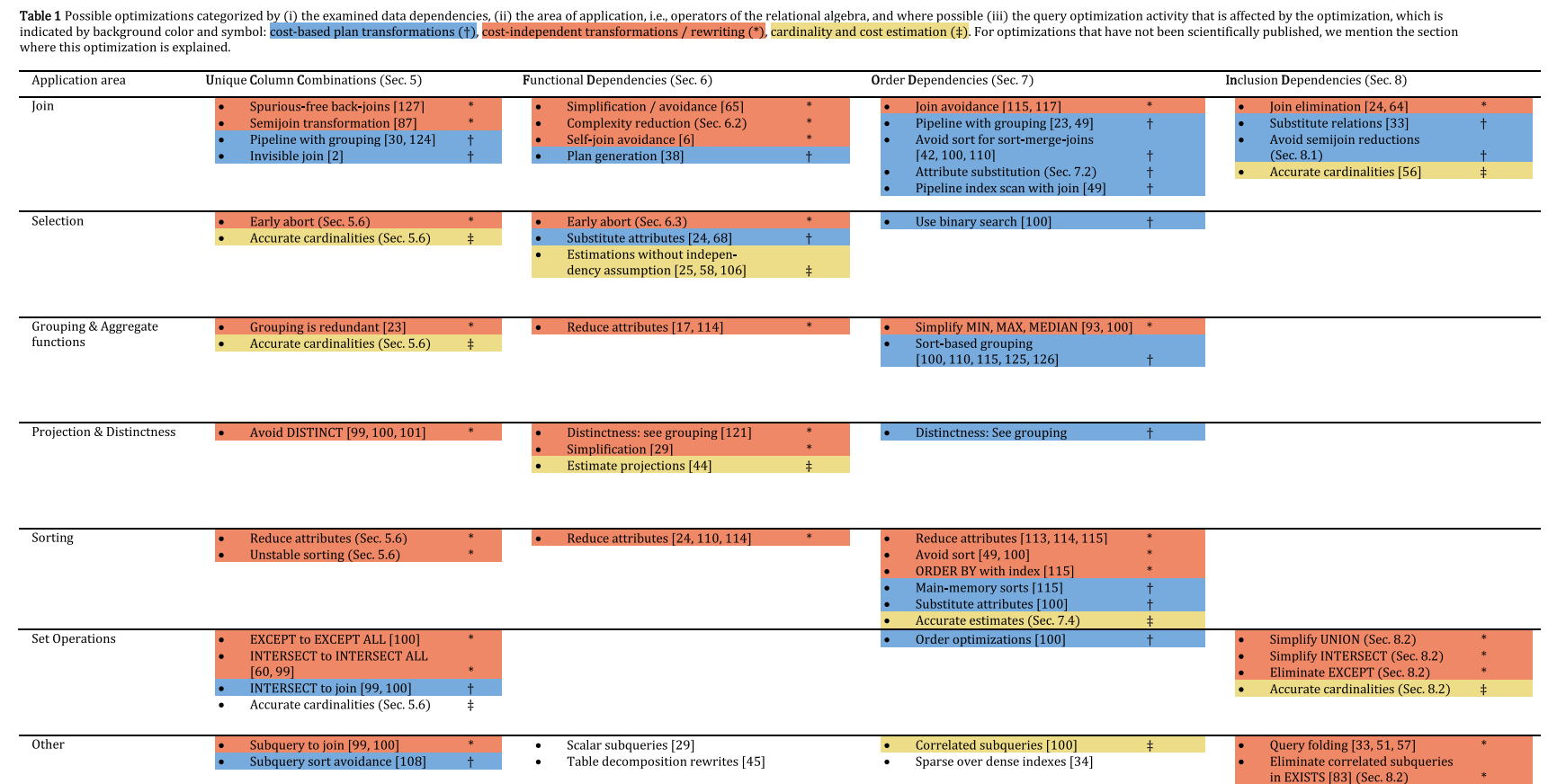

The original article can be found online at https://doi.org/10.1007/

Publisher's Note Springer Nature remains neutral with regard to s00778-021-00676-3.

Jan Kossmann

jan.kossmann@hpi.de

Thorsten Papenbrock

thorsten.papenbrock@hpi.de

Felix Naumann

felix.naumann@hpi.de

1 Hasso Plattner Institute, University of Potsdam, Potsdam,

Germany 